\title{
The Effect of Modifier on the Microstructure of the AlSi10CuNiMn Alloy
}

\author{
Jaromir Cais ${ }^{1 *}$, Jiri Heinrich' ${ }^{1}$ Klara Jirounkova ${ }^{1}$ \\ 1 Faculty of Mechanical Engineering, Jan Evangelista Purkyne University, 40096 Usti nad Labem, Czech Republic \\ *Corresponding author's e-mail: jaromir.cais@ujep.cz
}

\begin{abstract}
This paper deals with different types of modifiers and their effect on the microstructure of the Al-Si alloy. For the purposes of this research, strontium, antimony and calcium were used as the modifiers of the AlSi10CuNiMn alloy. Unmodified alloy was cast in order to be compared with the alloy modified by different modifiers in various concentrations. The results of this research were analysed via light and electron microscopy.
\end{abstract}

Keywords: Al-Si alloy, microstructure, modification, microscopy

\section{INTRODUCTION}

Al-Si alloys are currently ones of the most widespread casting alloys due to their mechanical and casting properties. They are usually used within automotive industry (casts of the engine parts, wheel discs, safety body parts, etc.) $[5,9]$. Nowadays, the trends within the automotive industry are becp,omg more ambitious (conversion of properties for high temperatures, corrosion resistance, etc.). These demands can be met by a combination of the alloying (5 and more elements) and a heat treating processes [3].

The mechanical, but even technological properties (mainly machinability) of the Al-Si alloy are mostly given by the morphology of the eutectic silicon grains eliminated within the microstructure of these alloys. Under usual conditions, the eutectic silicon is eliminated in the form of hexagonal plates, which are usually perceived as sharp-edged needles [8] in the plane of a metallographic sample. This very shape of silicon particles causes poor mechanical properties (mainly ductility) and worse machinability of these alloys. This fact can be significantly eliminated by the change of the particle morphology. The final shape of the eliminated silicon can be changed by the speed of cooling the casts (appropriate for small casts), by heat treatment or modification process $[1,7,8,10]$.

The modification process for the Al-Si alloys is based on the import of small amount of surface active substance into the melt. This substance interacts with silicon particles and affects their final shape. The most typical modifier (used since 1920s to 1970 s) was sodium. The main disadvantages of this modifier included its short-time effect (20 mins) and increase of the alloy gasification (causing more frequent occurrence of foundry defects) [4]. Both of these negative properties result from its low density (it flows upon the surface of the melt) and its high affinity to the oxygen (it burns upon the surface of the melt). This fact leads to a gradual transition from sodium to strontium. Strontium (usually added into melt in the form of AlSr10 master alloy) highly affects the morphology of crystallizing silicon, since the optimal shape of eliminated silicon is long fibre with round cross section. Another advantage of strontium is its density, which is very similar to aluminium (it flows evenly throughout the melt). Its disadvantage is the time-limited effect (1-2 hours) [2]. Therefore, the research involved seeking another modifier as a substitute for strontium. This alternative may include antimony or calcium (even though being described as an impurity) $[8,1]$. 


\section{EXPERIMENT}

The conducted experiment was focused on assessing the effect of three modifiers (strontium, antimony and calcium) on the microstructure of polycomponent AlSi10CuNiMn alloy. The chemical composition of this alloy is reported in Table 1 . The analysis of the chemical composition of this alloy was realised by using a Q4 TASMAN optical emission spectrometer.

Individual modifiers were added to the melt in the form of master alloy with $10 \%$ content of the modifier (AlSr10, AlSb10 and AlCa10). Three different concentrations of each modifier were used to create under-modified, optimally modified and over-modified state in four casts. All these variants are presented in Table $2[2-6,9]$.

The sample preparation consisted in melting the alloy in an electric furnace at $740^{\circ} \mathrm{C}$ (1 kg batch), gravitationally cast into preheated (at $720^{\circ} \mathrm{C}$ ) metal mold. Before casting, the alloy was cleansed by using refining salt (smear being removed from the surface of the melt). The final shape of the cast was a cylinder with diameter $20 \mathrm{~mm}$ and length $200 \mathrm{~mm}$ (four samples in each variant). The cast samples are presented in Figure 1. The metallographic samples were cut from the middle part of the cast

\section{MICROSCOPIC ANALYSIS}

The analysis of the cast sample microstructure was focused on documenting the morphology of the eliminated eutectic silicon particles. Another analysis focused on identifying and describing the distribution of modifiers within the microstructure of individual castings.

\section{Light microscopy}

The analysis of microstructure focused on the documentation of the eutectic silicon particle morphology excluded in the microstructure of an alloy was conducted by using an Olympus LEXT OLS 3100 confocal microscope.

The microstructure without any modifier is shown in Figure 2. This microstructure was formed by dendritic cells of solid solution $\alpha$ (light fields) and particles of eutectic silicon excreted in the form of hexagonal plates (in the shape of a sharp-pointed needle) in the non-modified state. The microstructure of an alloy with strontium used as a modifier captured in Figure 3. Adding strontium caused a change in the excluded silicon particles morphology. Even for $0.02 \mathrm{wt}$ \% silicon is excluded in the form of finer "fibres". Concentration $0.05 \mathrm{wt} . \%$ caused more significant change in morphology of eutectic silicon excluded in the form of very fine particles with a rounded cutsection. Adding 0.10 wt. $\%$ of $\mathrm{Sr}$ caused the rethickening of the silicon particles excluded in the form of needles (overmodification has occurred). Figure 4. shows the microstructure with antimony as a modifier.

Adding antimony as a modifier caused the least significant effect on the morphology of eutectic silicon particles. As the following figures suggest, silicon retained the shape of the needles, but they were refined (the most significantly for 0.15 wt.\%). Another $\mathrm{Sb}$ addition (0.30 wt.\%) caused the re-thickening of the silicon particles. The microstructure of an alloy modified by calcium is shown in Figure 5. The most significant effect on the eutectic silicon particles is shown by calcium with concentration of $0.30 \mathrm{wt} . \%$. This concentration caused silicon to crystalize in the form of amorphous particles. The concentration of $\mathrm{Ca}$ amounting to $0.70 \mathrm{wt} . \%$ caused, as in the case of other modifiers, a re-thickening of the silicon particles (overmodification).

\section{Electron microscopy}

In order to document the shape of the excluded silicon particles (not only in the plane of metallographic sample), the samples were subjected to deep etch. This etch was realized by $10 \%$ solution of $\mathrm{NaOH}$ heated at $70^{\circ} \mathrm{C}$. The time of etch was 60 seconds. The samples were also examined by using a Tescan Vega 3 scanning electron microscope.

The particles of eutectic silicon particles of the original alloy without using any modifier are presented in Figure 6. Silicon was excluded in the form of thin angular plates in this sample. Apart

Table 1. Chemical composition of the AlSi10CuNiMn alloy

\begin{tabular}{|c|c|c|c|c|c|c|}
\hline Chemical element & $\mathrm{Si}$ & $\mathrm{Cu}$ & $\mathrm{Ni}$ & $\mathrm{Mn}$ & $\mathrm{Fe}$ & $\mathrm{Al}$ \\
\hline Content [wt.\%] & 9.834 & 1.218 & 0.543 & 0.609 & 0.270 & base \\
\hline
\end{tabular}


Table 2. Variants of samples - modification state

\begin{tabular}{|c|c|c|}
\hline Variant & Modifier & $\begin{array}{c}\text { Content of modifier } \\
\text { [wt. \%] }\end{array}$ \\
\hline 1 & - & - \\
\hline 2 & \multirow{3}{*}{ Strontium } & 0.02 \\
\hline 3 & & 0.05 \\
\hline 4 & & 0.10 \\
\hline 5 & \multirow{3}{*}{ Antimony } & 0.05 \\
\hline 6 & & 0.15 \\
\hline 7 & & 0.30 \\
\hline 8 & \multirow{3}{*}{ Calcium } & 0.10 \\
\hline 9 & & 0.30 \\
\hline 10 & & 0.70 \\
\hline
\end{tabular}

from the particles of eutectic silicon, these figures also show complex intermetallic phases of Al-CuNi type. The effect of strontium used as a modifier (in different concentrations of $\mathrm{Sr}$ ) is shown in Figure 7. The strontium modification was most effective in terms of its effect on the change in the eutectic silicon morphology. With an addition of $0.05 \mathrm{wt} . \% \mathrm{Sr}$, the silicon in the microstructure was excluded in the form of very fine glazed fibres excreted in the interdendritic space. The modification by antimony is presented in Figure 8 . The effect of antimony on the change of silicon particles morphology was the least significant. For 0.15 wt.\% only a mild shape change of the excluded hexagonal plates to needles was detected. The particles of eutectic silicon of an alloy modified by calcium are shown in Figure 9. The particles of eutectic silicon were excluded in the form of tiny needles due to the modification effect.

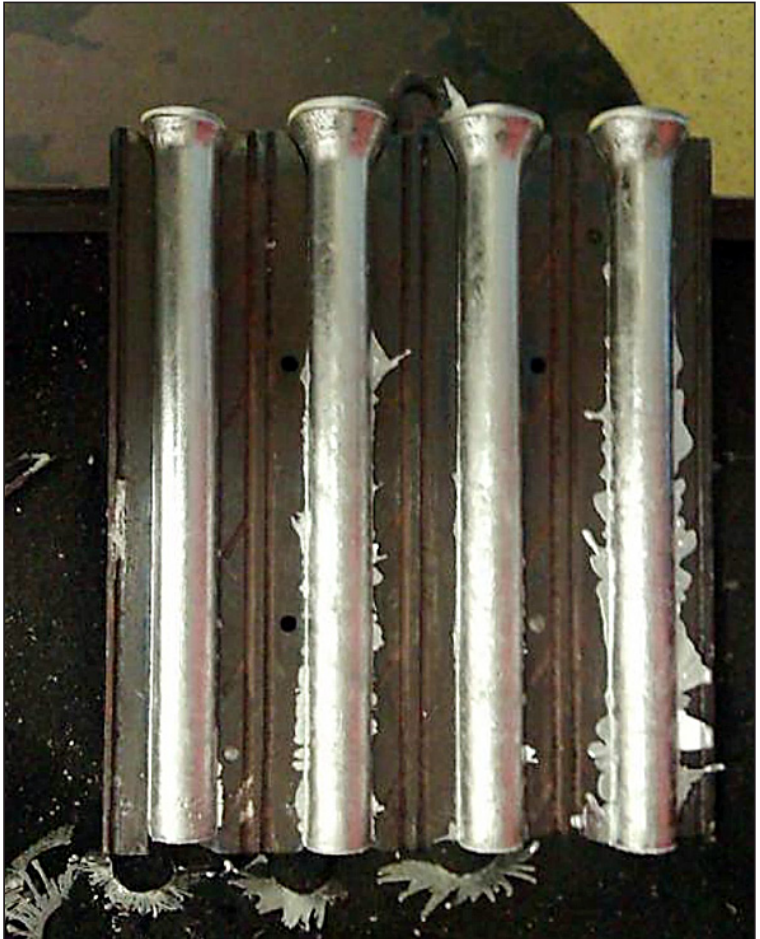

Fig. 1. Cast samples

In order to identify the modifier distribution, a Bruker X-Flash EDX analyser was used. The main focus was on the surface of silicon particles. Figure 10 shows an EDX analysis conducted on the eutectic silicon particles of an alloy modified by strontium.

The EDX analysis realised on the silicon excluded in the microstructure modified by antimony is presented in Figure 11. The EDX analysis on the silicon excluded in the microstructure modified by calcium is shown in Figure 12 .
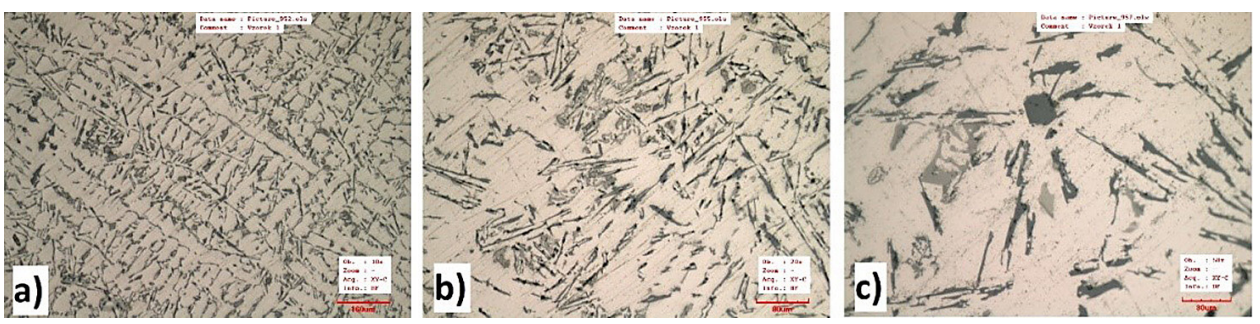

Fig. 2. Microstructure of original alloy: a) 100x mag., b) 200x mag., c) 500x mag.
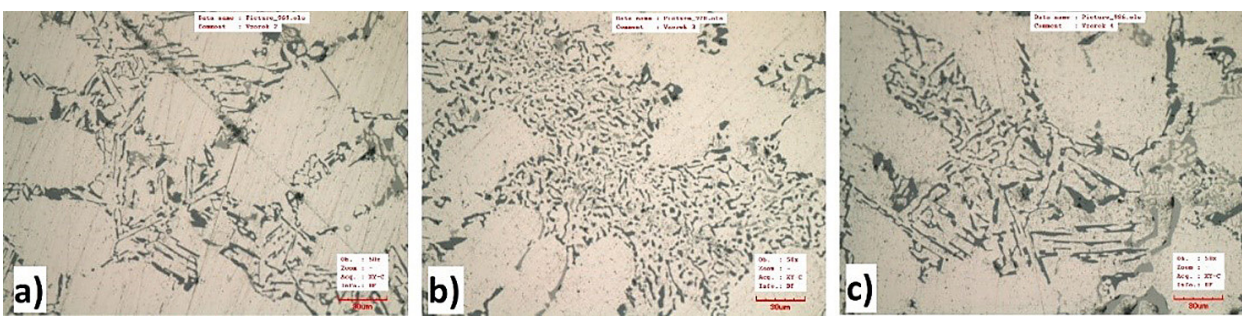

Fig. 3. Modification by Sr a) 0.02 wt. $\%$, b) 0.05 wt. $\%$, c) 0.10 wt. $\%$ 

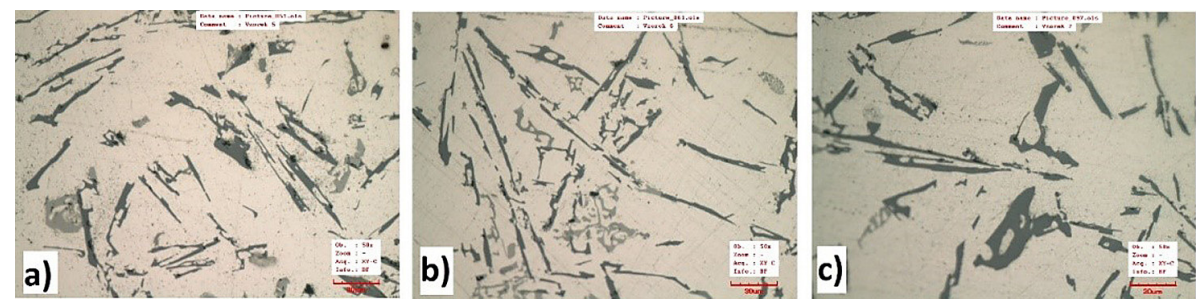

Fig. 4. Modification by Sb a) 0.05 wt.\%, b) 0.15 wt.\%, c) 0.30 wt.\%
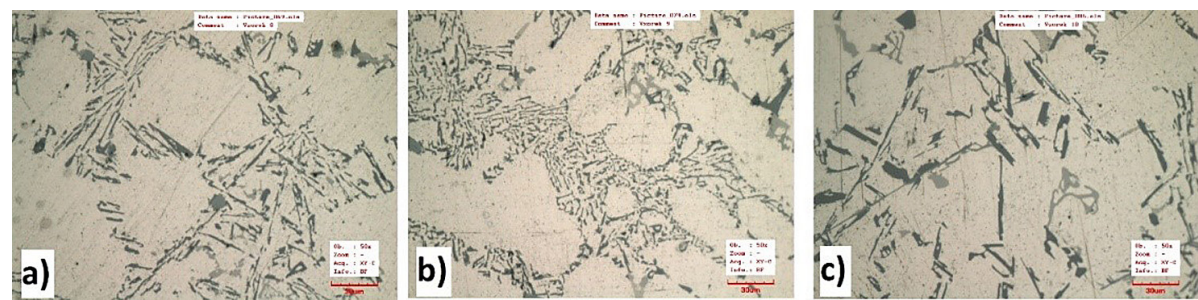

Fig. 5. Modification by Ca a) 0.10 wt.\%, b) 0.30 wt. $\%$, c) 0.70 wt.\%

\section{Discussion}

The addition of the modifiers into the melt has significantly changed the morphology of the eutectic silicon particles excluded within the polycomponent alloy microstructure. As a modifier, strontium has exhibited the most significant change of the eutectic silicon morphology. Its concentration at 0.02 wt. $\%$ was not sufficient. On the other hand, the concentration 0.10 wt.\% of $\mathrm{Sr}$ caused an over-modification of the alloy (exclusion of silicon shaped as a rough plates). The concentration of strontium as a modifier set at $0.05 \mathrm{wt} . \%$ caused the most significant change of the silicon morphology excluded in the form of tiny rounded fibres. The modification effect of antimony was the weakest one. For the concentration of $0.15 \mathrm{wt} . \%$, the effect on the change of eutectic silicon morphology was not very significant. For the concentration of $0.30 \mathrm{wt} . \% \mathrm{Sb}$, the thickening of the silicon particles was observed.
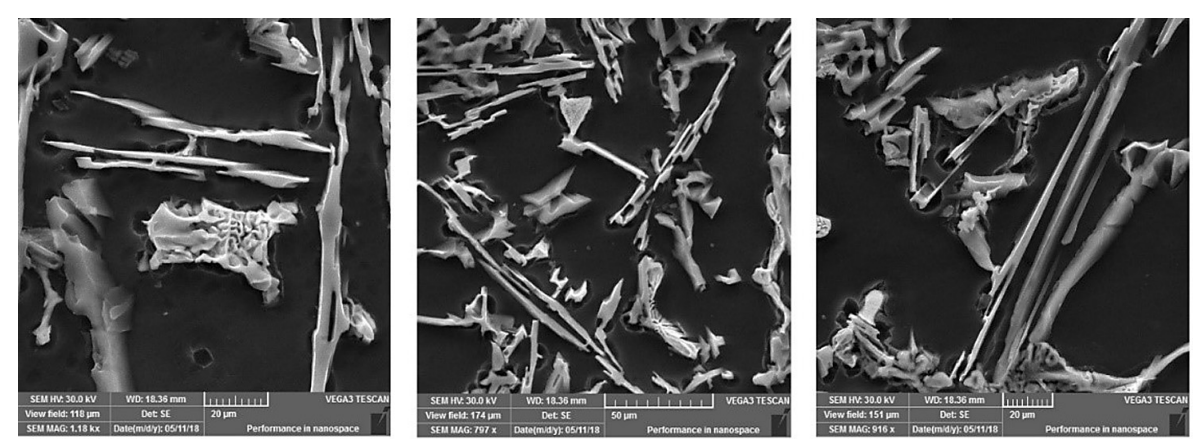

Fig. 6. Microstructure of an original alloy (SEM)
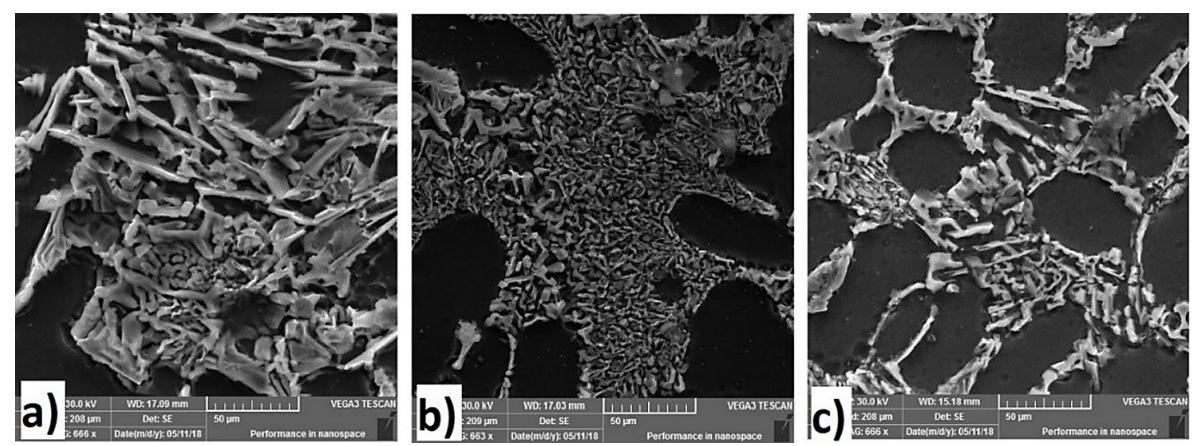

Fig. 7. Modifier Sr - a) 0.02 wt.\%, b) 0.05 wt.\%, c) 0.10 wt.\% (SEM) 

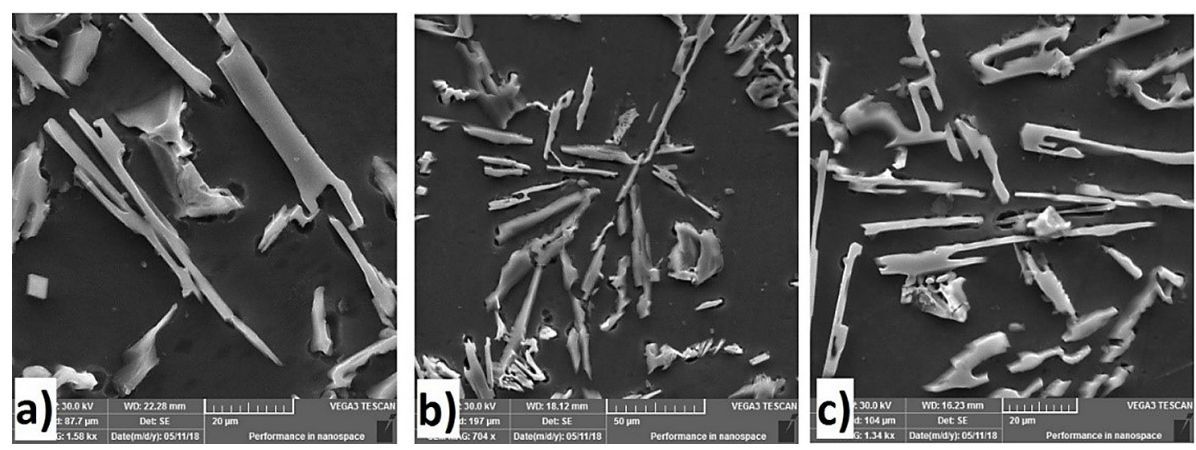

Fig. 8. Modifier $\mathrm{Sb}$ - a) 0.05 wt.\%, b) 0.15 wt.\%, c) 0.30 wt.\% (SEM)
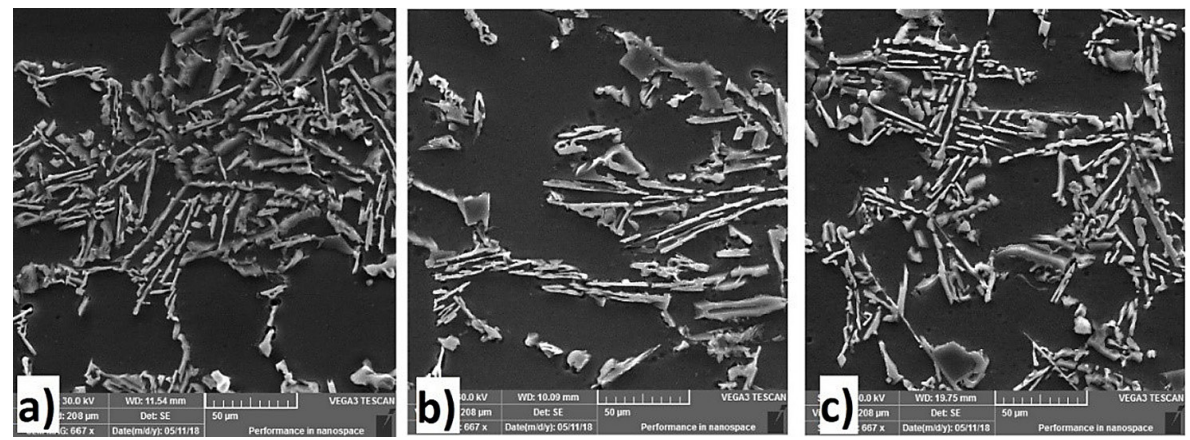

Fig. 9. Modifier Ca - a) 0.10 wt.\%, b) 0.30 wt.\%, c) 0.70 wt.\% (SEM)
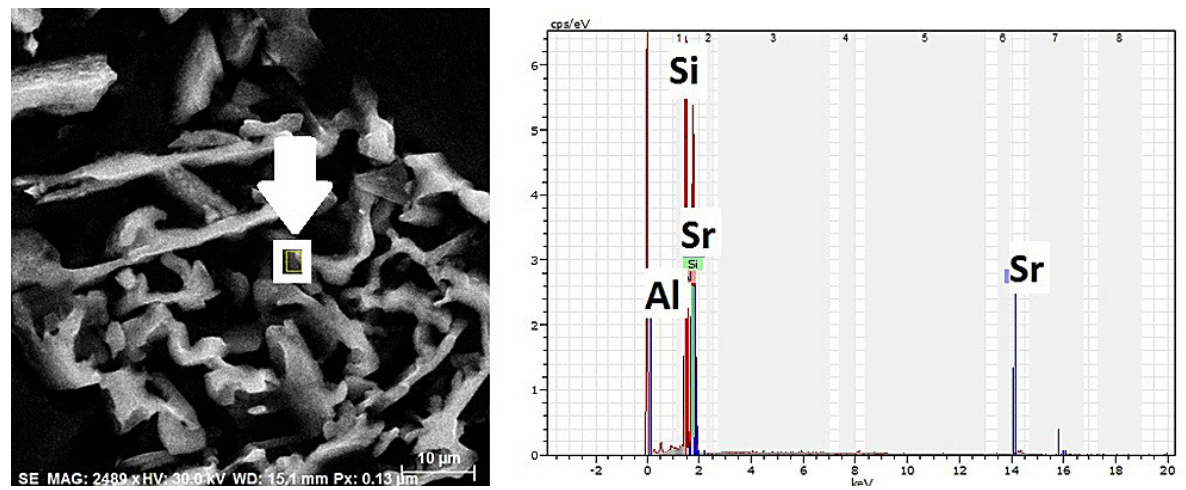

Fig. 10. EDX analysis of Si particle of an alloy modified by $\mathrm{Sr}$
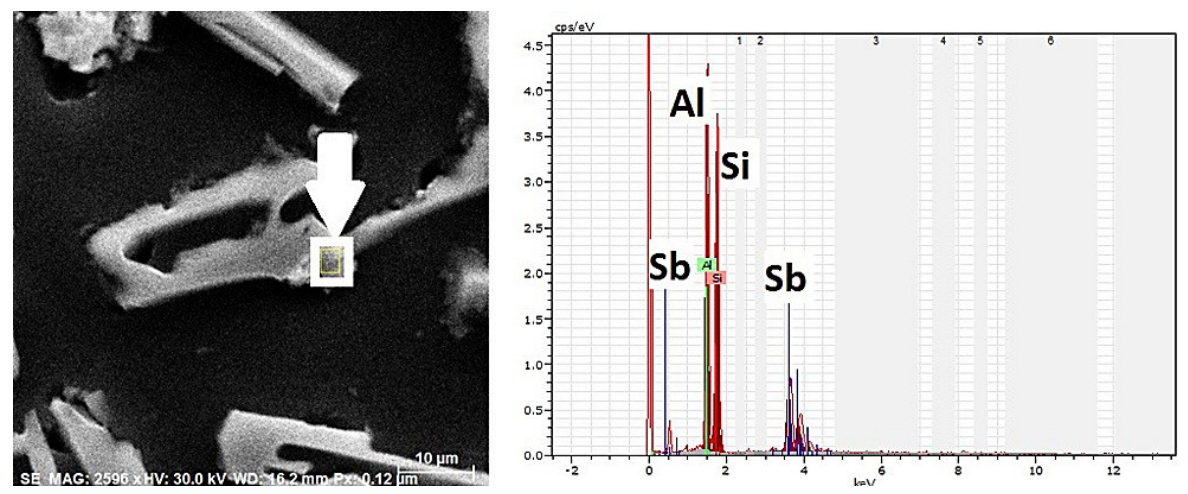

Fig. 11. EDX analysis of Si particle of an alloy modified by Sb 

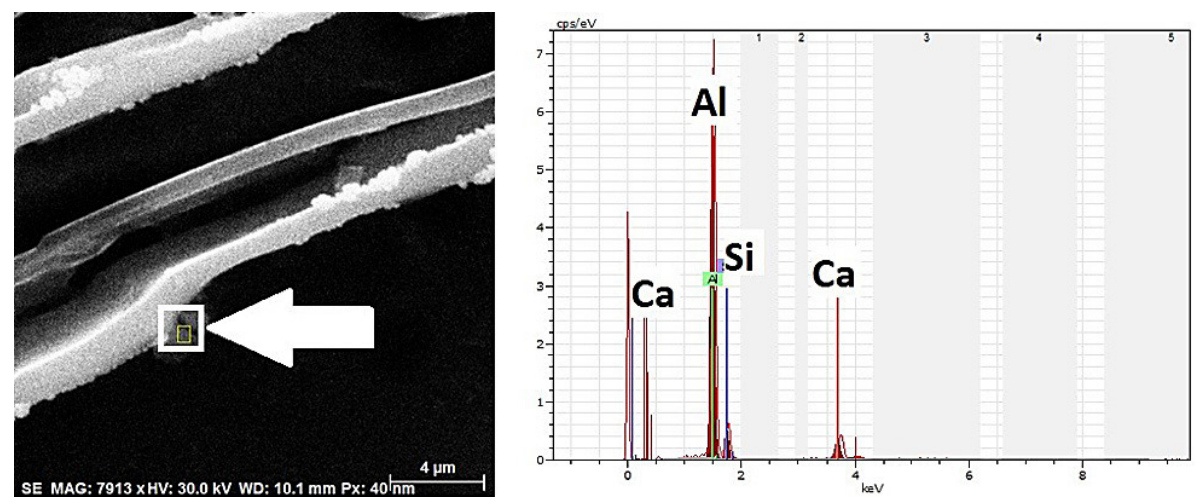

Fig. 12. EDX analysis of Si particle of an alloy modified by $\mathrm{Ca}$

The microstructure modified by calcium revealed the silicon excluded in form of fine plates. The modification effect was detected already for an alloy with $0.10 \mathrm{wt} . \%$ of calcium. The EDX analysis of the eutectic silicon particles for all modified samples revealed the presence of modifiers upon their surface. All used modifiers clearly react with the surface of eutectic silicon particles during its crystallization.

\section{CONCLUSIONS}

As a result of conducted experiment, strontium was revealed as the most suitable modifier of the AlSiCuNiMn alloy. Its concentration at 0.05 wt. $\%$ showed the most significant change in morphology of the eutectic silicon particles. For this concentration, the silicon is excluded in the form of fine fibres with round cross sections and the diameter ranged in micrometres and length of hundreds of micrometres. Due to this change in the microstructure, a significantly positive effect on the ductility of the alloy (which is low in the unmodified state) can be assumed.

Another significant effect of the eutectic silicon morphology was caused by using calcium as a modifier, which led to silicon particles being excluded in the form of fine plates. The modification effect was detected at $0.10 \mathrm{wt} . \%$ concentration.

The weakest modification effect was observed for using antimony as a modifier. The optimal concentration was set at $0.15 \mathrm{wt} . \%$. At this concentration, the silicon was excluded in the form of finer planes than at the original alloy (but much larger compared to the calcium as a modifier).

\section{Acknowledgement}

This work was supported by SGS No. UJEP-SGS-2018-48-001-2.

\section{REFERENCES}

1. Cais J., Náprstková N. Quality of Modification Process by Antimony Depending on Time for AlSi11Cu2 Alloy. Toyotarity - Change Management, 2014, 125-134.

2. Cais J., Weiss V., Svobodová J. Influence of Heat Treatment on Microstructure and Mechanical Properties of AlSi9CuMgNiMn Alloy. Proc. of 3rd Internationa Conference on Chemical Technology, Mikulov, Czech Republic 2015, 253-257.

3. Fatahalla N., Hafiz M., Abdulkhalek M. Effect of microstructure on the mechanical properties and fracture of commercial hypoeutectic Al-Si alloy modified with $\mathrm{Na}, \mathrm{Sb}$ and $\mathrm{Sr}$. Journal of Materials Science, 34, 1999, 3555-3564.

4. Knuutinen A., Nogita K., McDonald S., Dahle A. Modification offal-Si alloys with $\mathrm{Ba}, \mathrm{Ca}, \mathrm{Y}$ and $\mathrm{Yb}$. Journal of light metals, 1, 2001, 229-240.

5. Michna S̆., Honzátko R., Cais J. The Influence of Porosity on Mechanical Properties of Cast Produced from Al-Si alloys. Manufacturing Technology 13, 2013, 319-324.

6. Nogita K., Dahle A. Eutectic Growth Mode in Strontium, Antimony and Phosphorus Modified Hypoeutectic Al-Si Foundry Alloys. Materials Transactions, 42, 2001, 393-396.

7. Shabestari S.G., Shahri F. Influence of modification, solidification conditions and heat treatment on the microstructure and mechanical properties of A356 aluminum alloy. Journal of Materials Science, 39, 2004, 2023-2032.

8. Střihavková E., Weiss V., Michna Š. Study of the structure and fluidity of alloy of the Al-Si-Mg system with a different calcium Content. Metallurgist, 56, 2013, 708-713.

9. Xiufang B., Junhua Ch., Xiangfa L., Xiujuan Y., Furong R. The effect of magnesium on the antimony modification of Al-Si. JOM. 49, 1997, 35-36.

10. Xiufang B., Weimin W., Jingyu Q. Liquid structure of $\mathrm{Al} \pm 12.5 \% \mathrm{Si}$ alloy modified by antimony. Material Characterization, 46, 2001, 21-25. 